\title{
O Olhar dos Acadêmicos Concluintes do Curso de Licenciatura em Química da UEG sobre a Prática Pedagógica dos Professores Formadores
}

\author{
Márlon Herbert Flora Barbosa Soares* \\ Rogério Daniel Pereira Ramos**
}

Resumo

O objetivo deste artigo é discutir sobre a visão dos acadêmicos de Licenciatura em Química da Universidade Estadual de Goiás (UEG) a respeito da prática de professores formadores do referido curso e sua contribuição para a formação dos licenciandos. Para isso, realizamos cinco encontros, dois deles aqui apresentados e discutidos. Esta pesquisa é de natureza qualitativa, e a técnica utilizada foi a do grupo focal (GF), realizada com seis alunos do $7^{\circ}$ e $8^{\circ}$ períodos do ano de 2015 . Os dados foram analisados à luz da Análise Textual Discursiva (ATD), a partir de duas categorias selecionadas a priori: (a) relação entre as disciplinas específicas e pedagógicas e (b) relações entre as disciplinas de Prática de Ensino de Química (PEQ) e Estágio Supervisionado. Os resultados indicam a necessidade dos docentes repensarem sua prática educativa, considerando não apenas conhecimentos específicos, mas também pedagógicos, humanos e sociais, fundamentais para se formar com êxito um bom professor.

Palavras-chave: prática docente, professores formadores, UEG.

The View of the Concluding Academics of the UEG Chemistry Course on the Pedagogical Practice of Teaching Teachers

Abstract

The purpose of this article is to discuss the view of undergraduate students in Chemistry at the State University of Goiás (UEG) regarding the practice of the college professors and their contribution to the training of undergraduates. For this, we held five meetings, two of which are presented and discussed here. This research is of a qualitative nature, and the technique used was focus group (FG), carried out with six students from the 7th and 8th periods in 2015. The data were analyzed in the light of the Textual Discursive Analysis (TDA), from two categories selected a priori: (a) relationship between specific and pedagogical subjects and (b) relationships between the subjects of Chemistry Teaching Practice (CTP) and Supervised Internship. The results indicate the need for teachers to rethink their educational practice, considering not only specific knowledge, but also pedagogical, human and social, which are fundamental to successfully forming a good teacher.

Keywords: teaching practice, college professors, UEG.

\section{Introdução}

Nas últimas décadas, as discussões acerca da formação de professores formadores dos cursos de Licenciatura em Química no Brasil têm sido pauta de encontros, congressos e simpósios dessa área de ensino que se propõe a pensar um processo de formação que

\footnotetext{
* Doutor em Ciências (Química) - Universidade Federal de São Carlos. Professor da Universidade Federal de Goiás. E-mail: marlon@ufg.br.

*** Doutor em Química - Universidade Federal de Goiás. Professor da Universidade Estadual de Goiás. Email: rogerioramosueg@hotmail.com.
} 
saia do campo propedêutico, superando a prática tradicional e dicotômica, ainda muito presente em atividades desenvolvidas por docentes do ensino superior.

Como professor de Prática de Ensino de Química e orientador de Estágio Supervisionado do curso de Licenciatura em Química, no Campus de Ciências Exatas e Tecnológicas (CCET) da UEG, foi possível identificar problemas, apontados por licenciandos dos dois últimos períodos, em relação às dificuldades apresentadas no ensino de Química para alunos do ensino médio. Diante disso, lançamos indagações que nos permitiram compreender, a partir das narrativas feitas por acadêmicos, se os professores formadores vinculados a eles teriam a devida apropriação dos conhecimentos pedagógicos (PIMENTA, 2005; MALDANER, 2006; BENITE; BENITE; ECHEVERRIA, 2010).

É justamente a não convergência entre a linguagem adotada por esses docentes e aquela utilizada nas salas de aula do ensino médio que gera muitas limitações ao futuro professor, que conclui sua licenciatura e não se sente preparado para lidar com os desafios da docência. Por se tratar de uma questão complexa, que envolve o licenciando, o professor formador e o professor da escola, discutimos, a partir do olhar dos licenciandos, como eles avaliam a prática pedagógica dos professores formadores das disciplinas específicas e pedagógicas e quais as contribuições para sua formação.

Como nos adverte Mendes Sobrinho (2006), nos cursos de licenciatura, os conteúdos específicos e pedagógicos não têm sido trabalhados de forma integrada. Isso evidencia uma distância acentuada entre a teorização na formação do professor e sua atuação. Essa realidade, tão comum na prática dos professores formadores de Química da UEG, faz-nos perceber que, para esses docentes “[...] é um desafio presente e constante contextualizar com eficiência os conhecimentos teóricos, metodológicos e pedagógicos, capazes de transformar o ato de ensinar [...]" (CIRIACO, 2009), pois na universidade eles não receberam uma formação que lhes tornassem capazes de superar o hiato entre o conteúdo específico e o pedagógico.

A importância da formação dos professores formadores para a construção da identidade do curso de Licenciatura em Química da UEG

Quando nos referimos à construção da identidade do curso de Licenciatura em Química da UEG, o universo das discussões se amplia, uma vez que muitos que lecionam 
no curso não são licenciados e nunca tiveram, na graduação, no mestrado ou doutorado, disciplinas direcionadas para esse fim. Também as universidades, em seus editais de concursos, não exigem que os candidatos sejam licenciados, compreendendo uma questão antiga que direciona aos professores das disciplinas pedagógicas ou das faculdades de Educação a responsabilidade do preparo e da formação de professores (MALDANER, 1999). Na opinião desse autor, as dificuldades de aproximação dos professores das disciplinas específicas com as pedagógicas podem ser solucionadas a partir do momento em que a pesquisa for pensada como produtora do ensino, e as instituições exigirem esse tipo de produção. Assim, os professores assumirão com mais responsabilidade e seriedade essa outra vertente da ação docente.

As mudanças no Projeto Pedagógico de Curso (PPC) também são importantes, bem como a necessidade de repensar os conteúdos e todo o processo avaliativo. Mas o fundamental no processo de transformações e exigências do mundo contemporâneo é sermos capazes de assumir uma postura crítica e reflexiva de nossas ações em sala de aula, pois lidamos com o humano e, como tal, não podemos fugir daquilo que nos exige a própria realidade. Nessa perspectiva de trabalho conjunto, em 2015, foi aprovado o novo PPC do curso de Licenciatura em Química da UEG e reestruturada sua matriz curricular. A nova matriz contempla as especificidades da área, bem como a parte pedagógica, respeitando o número de horas destinadas ao estágio, às práticas curriculares e às atividades complementares.

Há também os componentes curriculares Trabalho de Curso (TC) I e II ofertados no $7^{\circ}$ e $8^{\circ}$ períodos, respectivamente. No PPC, constam que todos os TCs devem versar sobre temas relacionados ao ensino de Química, o que demonstra uma preocupação dos participantes da elaboração desse documento em propor diálogos entre as disciplinas específicas e as pedagógicas em todos os períodos, para fundamentar a matriz e abrir possibilidades para que os professores do curso possam realizar um trabalho interdisciplinar, contextualizado e colaborativo.

Essa tomada de consciência por parte dos professores formadores se dá de forma processual. Para isso, foi criado, na UEG, o Núcleo Docente Estruturante (NDE), voltado para debater sobre o ensino de Química e promover uma melhor e maior interação cognitiva e afetiva entre coordenação de curso, professores formadores de conteúdos específicos e pedagógicos e alunos em formação, possibilitando o entrecruzamento de 
olhares a respeito das temáticas que serão discutidas e novas formas de interpretação de ações cotidianas inerentes ao processo de ensinar e aprender.

Conforme salienta Tardif (2008, p. 14),

[...] o saber dos professores não é um conjunto de conteúdos cognitivos definidos de uma vez por todas, mas um processo em construção ao longo de uma carreira profissional na qual o professor aprende progressivamente a dominar seu ambiente de trabalho, ao mesmo tempo em que se insere nele e o interioriza por meio de regras de ação que se tornam parte integrante de sua 'consciência prática'.

Concordamos com o autor supracitado, pois entendemos que o ato de se transformar, no sentido de assumir as deficiências e buscar superá-las como professores formadores, significa “[...] concordar que não nos emancipamos sozinhos, mas com os outros e com os contextos onde nos inserimos" (SOUZA, 2005). É a partir desse pressuposto que defendemos a ideia da formação de professores do curso de Licenciatura em Química da UEG, por intermédio da pesquisa, como um caminho novo a ser percorrido, no sentido de que os saberes não são estáticos e nem destinados exclusivamente a alguns, mas elaborados e reelaborados cotidianamente.

\section{A pesquisa como eixo orientador das práticas formativas}

A formação docente ancorada nos princípios da formação pela pesquisa apresentase como uma alternativa de ensino promissora a ser vivenciada nas universidades, desde o início dos cursos de graduação. Nessa perspectiva de formação centrada na investigação, o professor, por meio de uma percepção reflexiva de sua prática, sente-se disposto a refletir, com vistas ao aprimoramento de sua atuação (MORAES; GALIAZZI, 2003). Assim, o ato de educar pela pesquisa

[...] implica em assumir a investigação como expediente cotidiano na atividade docente. $\mathrm{O}$ pesquisar passa a ser princípio metodológico diário de aula. $\mathrm{O}$ trabalho de aula gira permanentemente em torno do questionamento reconstrutivo de conhecimentos já existentes, que vai além do conhecimento de senso comum, mas o engloba e enriquece com outros tipos de conhecimento dos alunos e da construção de novos argumentos que serão validados em comunidades de discussão crítica. (MORAES; GALIAZZI, 2003, p. 238). 
Ao adotarmos essa noção de pesquisa, acreditamos que a escola seja o campo ideal para realização desse trabalho, por ser um ambiente propício para o desenvolvimento dos atuais e futuros professores pesquisadores que dela fazem e farão parte e, também, por possibilitar a inserção de vários professores formadores que até então não conheciam ou não conviviam com esse campo de estudo.

Por um lado, é claro que muitos formadores não querem ou não se identificam com esse tipo de atividade, preferindo continuar exercendo suas atividades tradicionais, aliás, essa é uma escolha que tem de ser respeitada. Por outro lado, alguns professores discutem propostas metodológicas para as aulas dos conteúdos específicos, no sentido de superarem a mera transmissão de conteúdos prontos e acabados, procurando "refletir sobre sua prática" (SCHON, 1992), no intuito de modificá-la, melhorando-a não só em seu próprio benefício, mas de todos aqueles futuros docentes que compõem a comunidade universitária.

A formação de professores pela pesquisa aproxima licenciandos e formadores, proporcionando a ambos possibilidades de convívio com a realidade do ensino médio e a aquisição de experiências e conhecimentos que possam ser transcritas em forma de artigos, monografias, dissertações e teses, contribuindo para que a área de ensino de Química na UEG possa alavancar, aproximando, dessa forma, a universidade da escola e superando a dicotomia professor e pesquisador, o que é o nosso propósito.

É nesse viés que apresentamos e analisamos os principais problemas relacionados à formação dos professores formadores de Química da Universidade Estadual de Goiás, Campus de Ciências Exatas e Tecnológicas, com sede em Anápolis (GO), e suas implicações na formação dos licenciandos. Tais questões relacionadas ao processo formativo dos professores formadores entram em pauta para discussões que arrolarão, no sentido de buscar respostas para interrogativas que venham contribuir para o avanço da formação pedagógica dos formadores, de forma que os acadêmicos adquiram identidades formativas para o exercício da docência.

Sendo assim, apresentamos algumas reflexões acerca da visão dos acadêmicos dos dois últimos períodos do curso sobre as contribuições dos professores formadores para formação dos futuros docentes da educação básica e as novas perspectivas idealizadas por esses concluintes para alcançar um cenário favorável à formação para docência. 


\title{
Método
}

Os fundamentos desta investigação estão ancorados nos marcos da pesquisa qualitativa, tendo como referência os princípios teórico-epistemológicos baseados na ideia de que os sujeitos sociais são pessoas reflexivas, que (res)significam suas experiências e ações nos vários contextos onde atuam. Nesse sentido, comungamos da ideia de Triviños (1987, p. 137) de que

\begin{abstract}
Os pesquisadores qualitativos estão preocupados com o processo e não simplesmente com o resultado e o produto, uma vez que [...] a pesquisa qualitativa não admite visões isoladas, parceladas, estanques. Ela se desenvolve com a interação dinâmica, retroalimentando-se, reformulando-se constantemente, por meio da coleta de informações.
\end{abstract}

Entendendo a formação de formadores de professores de Química como um processo, consideramos fundamental analisar a fala dos sujeitos participantes deste estudo, isto é, dos seis alunos, formandos acadêmicos do $7^{\circ}$ e $8^{\circ}$ períodos. $\mathrm{O}$ método escolhido para nortear nosso estudo foi o da Análise Textual Discursiva, proposta por Moraes e Galiazzi (2013). Sobre esse método, os autores afirmam se tratar de

[...] um processo integrado de análise e de síntese que se propõe a fazer uma leitura rigorosa e aprofundada de conjuntos de materiais textuais, com o objetivo de descrevê-los e interpretá-los no sentido de atingir uma compreensão mais complexa dos fenômenos e dos discursos a partir dos quais foram produzidos. (MORAES; GALIAZZI, 2013, p. 114).

A partir dessa compreensão e entendimento da pesquisa como processo reconstrutivo de discursos sociais, procedemos à realização das análises textuais dos discursos dos acadêmicos concluintes, materializados pelas narrativas selecionadas, para, por meio delas, refletir sobre a realidade da Licenciatura em Química da UEG, que perpassa, entre outros fatores, a formação dos professores formadores e a própria identidade do curso. Tais narrativas, oriundas de um instrumento de coleta de dados conhecido como grupo focal, foram registradas nos encontros filmados e, posteriormente, transcritas para a análise sugerida.

A coleta de dados, realizada ao longo dos cinco encontros entre o pesquisador e os seis acadêmicos, focaliza a temática relacionada à formação inicial e continuada de professores de Química da UEG e ressalta as visões desses futuros egressos acerca das 
contribuições da universidade e dos professores formadores para sua formação e possível atuação no mundo do trabalho como professores dessa área do ensino médio. O GF, conhecido como técnica de coleta de dados resultante da pesquisa qualitativa, também foi usado por compreender uma metodologia apropriada e se apresentar como uma oportunidade de reunir estudantes num mesmo espaço, por meio do compartilhamento de significados socialmente estabelecidos (GATTI, 2005).

Ao todo, foram cinco encontros realizados entre o pesquisador e os acadêmicos divididos em 5 temáticas ( 1 relação entre as disciplinas específicas e pedagógicas; 2 visão dos acadêmicos sobre o curso; 3 dicotomia teoria x prática; 4 planejamento; 5 relação entre as disciplinas PEQ e Estágio Supervisionado). Porém, demos ênfase ao primeiro e o quinto, haja vista que os temas abordados estão estreitamente ligados à prática pedagógica dos professores formadores e são tópicos basilares para se discutir em um curso de formação de professores de Química. Os participantes do grupo foram identificados de A1 a A6.

Conforme Moraes e Galiazzi (2013), os seguintes passos foram executados ao analisarmos as filmagens dos grupos focais: 1 Unitarização: fragmentação dos textos oriundos das reuniões com o GF, em unidades de significado, 2 Categorização: agrupamento das unidades de significado de acordo com a semelhança semântica e 3 Captando o novo emergente: comunicação a partir do metatexto com produções escritas de natureza descritiva e interpretativa. Para a análise das narrativas, iniciamos com o processo de unitarização, no qual se buscou identificar semelhanças semânticas entre as falas dos participantes sobre cada categoria a priori apresentada no início de cada encontro.

Foram propostas duas categorias que "[...] correspondem a construções que o pesquisador elabora antes de realizar a análise propriamente dita dos dados" (MORAES; GALIAZZI, 2003, p. 198). Nesse sentido, as discussões sobre os resultados foram realizadas com base em duas categorias de análise, a saber: (a) relação entre disciplinas específicas e pedagógicas; (b) relações entre as disciplinas de Prática de Ensino de Química e Estágio Supervisionado. A partir dessas categorias, foi construído um metatexto que se refere à formação pela pesquisa, por meio de atividades de orientação/coorientação. 


\title{
A) Relação entre as disciplinas específicas e pedagógicas
}

Nesse encontro, foi apresentado aos acadêmicos o objetivo da pesquisa e explicado o que era o GF. Em seguida, solicitou-se aos estudantes que se sentissem à vontade para expressarem suas opiniões a respeito do tema tratado nesse e nos demais encontros. A primeira reunião referiu-se à falta de relação entre as disciplinas específicas do curso com as disciplinas pedagógicas. Sobre o modo como enxergam essa relação, os acadêmicos A2 e A6 disseram:

\begin{abstract}
A2: Eu vejo que a maior dificuldade que a gente tem aqui está relacionada à parte didática, ou seja, ser professor e o conteúdo de Química. Eles não se ligam. As matérias tipo Orgânica e Inorgânica são baseadas na memorização e numa forma mais tradicional. Você presta atenção na aula e faz provas valendo $100 \%$ da nota que é uma questão massacrante. E tem um outro ponto, um outro foco, que é a parte de ser professor. Nós temos que melhorar a forma de dar nossas aulas, ser bem informado, inovador e dar aulas contextualizadas. Eu vejo que na universidade os professores de conteúdo de Química e os professores de conteúdo didático não trabalham em conjunto. Nós vemos que é separado. Enxergamos dois extremos, aprendemos duas coisas separadas e sem ligação.

A6: É importante sim os conteúdos específicos para a nossa formação, principalmente para quem irá fazer mestrado. $\mathrm{O}$ fato é que quase todos os nossos professores de Química são bacharéis e sem nenhuma experiência didática com alunos do ensino médio.
\end{abstract}

A partir das narrativas, notamos uma problemática relacionada à formação inicial do professor formador, que se encontra fundamentada nas concepções curriculares dos cursos de Bacharelado em Química, o que se contrapõe às características de um curso de licenciatura devido ao seu caráter tradicional e positivista. Diante do exposto, A1 sinaliza o lugar que os cursos de Licenciatura em Química ocupam nas instituições universitárias, salientando a "desarticulação entre a formação na área específica e a formação para a docência" (LIBÂNEO, 2015). No que diz respeito a essa falta de aproximação entre as disciplinas, observamos que uma das consequências para o alcance da consolidação do curso, que tem como propósito formar professores de Química para atuarem na educação básica, é a ausência de um trabalho específico voltado para formação adequada dos acadêmicos do curso de Licenciatura em Química da UEG. 
Apoiamo-nos em estudos de Pimenta (2005), mencionados por Libâneo (2015), que propõem três tipos de saberes articulados entre si e necessários para a formação do bom professor: o saber da matéria, isto é, o conhecimento do professor sobre a disciplina que ensina; o saber pedagógico, que diz respeito ao conhecimento que resulta da reflexão confrontada entre o saber da matéria e os saberes da educação e da didática; o saber da experiência, construído a partir de experiências vivenciadas pelo professor e pelo aluno, incluindo suas representações sobre a escola e o ensino.

Compreender a particularidade de cada um desses saberes da formação docente e perceber a relação próxima entre eles é um desafio constante para professores das disciplinas específicas e pedagógicas. Pensar dessa maneira significa superar uma visão pouco sólida entre a especificidade disciplinar e pedagógica no currículo dos cursos de licenciatura (LIBÂNEO, 2015). Concordamos com Pimenta (2005) quando esta assinala que existe uma dissociação entre a formação docente e o conhecimento disciplinar das ciências, ou seja, nem sempre os professores que ministram aulas nos cursos de licenciatura têm formação adequada para desenvolverem uma prática que vai além do domínio dos conteúdos químicos.

No relato de A2, isso é evidenciado como uma dificuldade a ser superada para melhoria da qualidade do curso de Licenciatura em Química da UEG. Sobre essa questão, Benite, Benite e Echeverria (2010, p. 259) afirmam que

[...] não há preparação formal para o formador, e que em muitas áreas do conhecimento os processos seletivos relacionados à contratação docente em Instituições de Ensino Superior (IES) priorizam as linhas de pesquisa na área técnica. Em consequência, os processos de desenvolvimento profissional ficam na dependência de cada instituição e de como esta concebe a formação do formador.

A Lei de Diretrizes e Bases da Educação Brasileira (LDB) nº 9.394, de 20 de dezembro de 1996, trata da formação dos professores do ensino superior de forma pontual e superficial. Conforme essa normativa, a docência não é concebida como formação, mas como preparação para o exercício do magistério superior, que deverá ser realizada prioritariamente nos cursos de pós-graduação strictu sensu como preparação para o exercício do magistério superior. Essa preparação ocorre em cursos rápidos de 45 ou 60 horas, não sendo suficientes para profissionalizar para a docência na universidade (PIMENTA, 2005). 
Ainda que exista essa deficiência na lei, é importante que as Instituições de Ensino Superior repensem as práticas dos cursos de licenciatura, como a formação do professor formador, responsável pela capacitação dos profissionais da educação básica. No que se refere ao curso de Licenciatura em Química da UEG, algumas iniciativas foram propostas pela atual coordenadora, como, por exemplo, a criação do Laboratório Interdisciplinar de Pesquisa em Ensino de Ciências (LIPEC). Ações inovadoras como essa têm alcançado resultados promissores, uma vez que a maioria dos profissionais tem participado com mais compromisso de discussões e reflexões propostas pela coordenação de curso do NDE.

B) Relações existentes entre as disciplinas de Prática de Ensino de Química e o Estágio Supervisionado

O foco desse encontro foi direcionado à percepção dos acadêmicos sobre as relações existentes entre as disciplinas de Prática de Ensino e Estágio Supervisionado. Para tanto, uma breve exposição sobre a importância do estágio na formação do licenciando foi realizada, apontando também a relevância da disciplina prática de ensino como ponto de referência e apoio para o desenvolvimento do estágio. Diante do exposto, foram lançadas algumas questões para que os alunos expressassem suas opiniões sobre como se sentiam após terem concluído todos os estágios exigidos pela instituição para conclusão do curso. Os questionamentos iniciais foram os que se seguem: 1) As Práticas de Ensino I, II, III e IV contribuíram para a realização do estágio? 2) O estágio proporcionou momentos de vivência com a realização de pesquisas e publicações ou produção de TC? 3) Você se sente preparado para assumir uma sala de aula após o término do curso?

Essas questões guiaram nossa conversa, e as falas registradas revelaram que se faz urgente repensar a organização e a estruturação dos estágios da Licenciatura em Química da UEG. A seguir, apresentamos as falas de A1, A2, A3 e A4.

\footnotetext{
A1: Criar situações para que tenhamos uma ideia de como vamos dar uma aula no ensino médio ao sairmos da universidade, porque não é isso que temos visto aqui. Na disciplina de PEQ IV, ministrada nesse último semestre, tivemos melhores orientações sobre como preparar uma aula contextualizada, mas, nas três que tivemos em períodos anteriores, não, e se eu fosse para a escola, ficaria meio perdida. Não ficaria tanto porque a gente pesquisa, busca atualizações, mas seria mais difícil.
} 


\begin{abstract}
A2: A disciplina que mais contribui para o nosso estágio foi a PEQ-IV. As aulas de PEQ e Estágio foram meio que misturadas, ficávamos nas duas aulas de PEQ e nas duas de Estágio falando de ser professor e ao mesmo tempo sobre o que acontecia no estágio. Era muita coisa, várias escolas, vários projetos, vários temas, vários experimentos, e todos queriam falar sobre as suas experiências e nem sempre dava tempo de fazer tudo nas aulas de estágio e acabava pegando as aulas de PEQ.
\end{abstract}

A3: Trazíamos nossas angústias e ansiedades vividas na sala de aula no campo do estágio para serem compartilhadas com os colegas e com a professora nas aulas de PEQ. A professora nos ajudou muito, pois ela também é professora do ensino médio e sempre nos dava dicas de como ela fazia nas suas aulas. Ela nos ajudou apresentando um cronograma de aulas experimentais com a utilização de materiais alternativos de forma que não fugisse à realidade vivida pelos alunos.

A4: Todos os professores de PEQ deveriam deixar as teorias para as disciplinas pedagógicas como a Didática e os Fundamentos do Ensino de Química. As disciplinas de prática de ensino deveriam nos confrontar sobre como nós daríamos uma aula, qual a melhor tentativa, qual o melhor meio, nos preparar mais para chegarmos na sala de aula dominando o conteúdo.

A amplitude do estágio supervisionado nos cursos de licenciatura atinge dimensões complexas que envolvem o sistema organizacional das escolas públicas e também o das universidades. Para estreitar essa relação, Garcez et al. (2011, p. 1-2) destacam que:

[...] o estágio configura-se como importante locus de construção dos saberes docentes, tendo em vista sua característica como espaço de interlocução entre a universidade e o contexto da educação básica. Sob este enfoque, ressaltamos que o desenvolvimento das atividades de estágio não deve se estabelecer em um único sentido, ou seja, da universidade para a escola, mas em situações de troca que propiciam a construção dos saberes docentes de todos os envolvidos no processo: estagiários, professor regente e professor formador.

Compartilhamos da ideia proposta pelos autores quando defendem o estabelecimento de uma mão dupla que deve existir entre a universidade e a escola, uma vez que o estagiário, quando bem-sucedido nas atividades realizadas no campo de estágio, traz contribuições significativas para melhoria da qualidade do ensino oferecido nas escolas. No caso da UEG, esse é um dos grandes desafios do curso, e, talvez por isso, os relatos demonstram que, ao concluírem o curso de Licenciatura em Química, os acadêmicos não se sentem preparados para serem professores. Frente a esse cenário, questionamos: $\mathrm{O}$ que fazer para construirmos uma identidade de curso que realmente forme bons professores de Química? 
Acreditamos que a ruptura com o modelo de formação ainda pautado na racionalidade técnica seja o primeiro passo. Outro ponto se refere à superação das questões burocráticas do estágio, como preenchimento de fichas, diários e produções de relatórios, que, muitas vezes, parecem ser mais importantes do que o próprio estágio. Para amenizar esse problema, adotamos a pesquisa colaborativa por meio da coorientação, possibilitando um maior contato dos formadores e acadêmicos com as situações vividas nas escolas, criando, dessa forma, uma ponte que permita uma maior aproximação e interação entre escola e universidade, favorecendo o enriquecimento das práticas formativas desenvolvidas nas aulas das disciplinas específicas e pedagógicas.

Um aspecto importante apontado nas falas de A1 e A2 se refere às contribuições da disciplina Prática de Ensino e Química IV para realização do estágio nas escolas de nível médio. A professora dessa disciplina em muito contribuiu com os acadêmicos, pois ela também é docente no ensino médio e traz uma vasta experiência de trabalho vivida na educação básica, auxiliando de forma promissora o desenvolvimento das aulas dadas pelos acadêmicos no período de regência.

Nas falas de A1 e A4, há uma reivindicação aos professores formadores para que lhes ensinem a dar uma boa aula sobre os conteúdos do ensino médio. Salientamos que, embora saibamos das dificuldades apontadas sobre a formação desses educandos, a maioria bacharéis, é preciso também pontuarmos que nem sempre saber dar uma boa aula é a solução para os problemas vividos no cotidiano da escola. Os momentos de reflexão vividos em sala de aula, na universidade, podem e devem ser usados para discutir e aprender como dar boas aulas de Química, sem esquecer que não só os saberes da docência são essenciais para se alcançar o sucesso profissional. As questões afetivas que envolvem as relações entre professores e alunos também favorecem o alcance de um clima harmonioso e propício para a construção do conhecimento pelas pessoas em formação (MAGALHÃES, 2011; TARDIF; LESSAR, 2012).

Para implantarmos essa ideia, sugerimos que a UEG proponha uma política mais direcionada às atividades de iniciação científica e desenvolvimento de projetos de ensino e pesquisa, com oferta de mais bolsas aos graduandos, e ofereça a todos os docentes efetivos do curso a opção de regime de trabalho como dedicação exclusiva para que tenham melhores condições de criar momentos de estudos coletivos, com vistas à integração entre os professores das diversas disciplinas e com os acadêmicos, superando 
o hiato existente entre as áreas específicas e pedagógicas, fortalecendo o curso com esse novo modelo de trabalho.

É importante adotar tais medidas, porque o contexto escolar atual exige que os cursos de professores formadores não direcionem as práticas docentes apenas para o ensino, pois, dessa forma, os futuros professores não conseguirão resolver os problemas e os desafios pertinentes que surgirão no cotidiano de sua sala de aula, por ausência de uma atividade questionadora que os impede, muitas vezes, de solucionar problemas e propor caminhos para superação das dificuldades encontradas em sua ação educativa. Nessa perspectiva de formação, Demo (1997), Bortolini (2009), Echeverria, Benite e Soares (2010), Moraes e Galiazzi (2013) apontam a existência da pesquisa como imprescindível na universidade, pois são nesses espaços que ocorrem a sistematização do conhecimento.

\section{Notas conclusivas}

A partir dos dados resultantes advindos desta pesquisa, foi possível identificar que o curso de Licenciatura em Química da UEG apresenta uma identidade voltada para o bacharelado, ao invés de ser direcionado à formação de professores (licenciatura). Evidenciou-se a presença de obstáculos epistemológicos e pedagógicos, marcados pelas dicotomias específico/pedagógico, ensino/pesquisa e currículo instituído/currículo vivenciado.

Observa-se, portanto, principalmente por parte dos docentes formadores das áreas específicas, a necessidade de reflexão sobre o próprio papel na formação dos licenciandos. É importante problematizar em que condição os professores formadores pautam as suas aulas. Diante das análises, identificamos a necessidade de haver uma imprescindibilidade que compreende a formação pedagógica no processo acadêmico inicial, cujos sentidos poderiam nortear se os nossos futuros professores estão situados em seu tempo e espaço ante as complexidades advindas da atualidade e no recinto da sala de aula.

Ao discutirem os aspectos didáticos e pedagógicos relacionados ao processo de ensino e aprendizagem de Química que ocorre na UEG, faz-se indispensável discutir e 
repensar o papel e a importância das disciplinas específicas e pedagógicas do curso que contribuirão para que os acadêmicos exerçam sua profissão como futuros docentes.

Romper com as dicotomias presentes no curso são tarefas urgentes a serem deliberadas pelos professores, buscando, assim, encontrar novas possibilidades de realização de trabalho com mais consciência social, fundamentadas em propostas curriculares derivadas de um trabalho conjunto entre o embasamento teórico sobre os conhecimentos químicos, bem como os relacionados ao ensino de Química.

Essas ações serão efetivadas desde que os professores das disciplinas de conteúdos científicos específicos tenham consciência de que os conteúdos químicos que ministram devem ser pedagogicamente transformados, de forma a cooperar para que os acadêmicos possam aplicar tais conhecimentos em sala de aula, onde já atuam como professores titulares ou ainda como estagiários.

É preciso que os professores formadores busquem se aprimorar constantemente através da formação continuada, objetivando se apropriar de novas metodologias, para que, assim, redimensionem sua prática pedagógica e sua visão epistemológica de ensino e de aprendizagem. Isso sem dúvida representa um grande desafio aos professores do curso, no sentido de proporcionar aos acadêmicos uma aula mais dinâmica, interessante, participativa e que, de fato, irá auxiliá-los em sua prática educativa nas escolas de nível médio.

Para que isso ocorra, é necessário que o professor formador seja um pesquisador em sala de aula e instigue os licenciandos para que sigam esse ofício, descobrindo o fato científico por meio das etapas que a pesquisa nos propõe, relacionando-o com a vida cotidiana. Para alcançar esse propósito, é preciso que as aulas aconteçam de forma a aproximar os alunos da realidade vivida nas escolas, por meio de atividades propostas pelos professores de todas as disciplinas, em especial, das pedagógicas. Sendo assim, constrói-se socialmente a ideia da importância efetiva da Ciência Química no cotidiano do aluno, interagindo com seu meio sociocultural, pois adotar essa ideia de trabalhar com o concreto (o que ele traz da sua vivência) é estar partindo do pressuposto de que é necessário assumir a prática do concreto como forma de atingir o abstrato. Pensando assim, será possível não supervalorizar o cotidiano em função do científico, mas preparar o aluno para alcançar os conhecimentos de caráter científico. 
É nessa perspectiva que apresentamos o novo emergente resultante deste estudo, por meio da realização da pesquisa (orientações/coorientações) para escrita do TC. Esperamos que essas atividades resultem no enriquecimento da prática pedagógica dos professores formadores e licenciandos, aproximando a escola e a universidade, na perspectiva do trabalho conjunto e colaborativo, das trocas de conhecimentos e culturas que possibilitem a promoção de um processo de formação de professores mais próximo das reais condições das escolas e das reais demandas de formação profissional.

\section{Referências}

BENITE, C. R.; BENITE, A. M. C.; ECHEVERRIA, A. R. A pesquisa na formação de formadores de professores: em foco, a educação química. Química Nova na Escola, v. 32, p. 259-266, 2010.

BORTOLINI, M. R. A pesquisa na formação de professores: experiências e representações. 2009. Tese (Doutorado em Educação) - Universidade Federal do Rio de Janeiro, Rio de Janeiro Brasil, 2009.

BRASIL. Lei n ${ }^{\circ}$ 9394, de 20 de dezembro de 1996. Estabelece as diretrizes e bases da educação nacional. Presidência da República, Casa Civil, Subchefia de Assuntos Jurídicos, Brasilia, DF, 1996. Disponível em: http://www.planalto.gov.br/ccivil_03/eis/19394.htm. Acesso em: 10 ago. 2020.

CIRIACO, M. G. S. Práticas pedagógicas de professores de química: interfaces entre formação inicial e continuada. 2009. 132f. Dissertação (Mestrado em Educação) Universidade Federal do Piauí, 2009.

DEMO, P. Educar pela pesquisa. Campinas: Autores Associados, 1997.

ECHEVERRIA, A. R.; BENITE, A. C. M.; SOARES, M. H. F. B. Formação superior em química no Brasil: práticas e fundamentos curriculares. Ijuí, RS: Ed. Unijui, 2010.

GARCEZ, E. S. C.; GONÇAlveS, F. C.; AlveS, L. K. T.; ARAÚJO, P. H. A.; SOARES, M. H. F. B.; MESQUITA, N. A. S. O estágio supervisionado em química: possibilidades de vivência e responsabilidade com o exercício da docência. Alexandria, v. 5, p. 149-163, 2012.

GATTI, B. Grupo focal na pesquisa em ciências sociais e humanas. Brasília: Líber livro, 2005.

LIBÂNEO, J. C. Democratização da escola pública: pedagogia crítico-social dos conteúdos. São Paulo: Loyola, 1985. 
LIBÂNEO, J. C. Formação de professores e didática para desenvolvimento humano. Educação \& Realidade, v. 40, p. 629-650, 2015.

MAGALHÃES, S. M. O. Oralidade em documentos oficiais do ensino médio. Linhas Críticas [on-line], v. 17, p. 151-162, 2011.

MALDANER, O. A. A pesquisa como perspectiva de formação continuada do professor de química. Química Nova, v. 22, p. 289, 1999.

MALDANER, O. A. Formação inicial e continuada de professores de química: professores/pesquisadores. Ijuí: Unijui, 2006.

MENDES SOBRINHO, J. A. C. Formação de professores e práticas docentes: olhares contemporâneos. Autêntica: Belo Horizonte, 2006.

MORAES, R.; GALIAZZI, M. C. Análise textual discursiva. 2. ed. Ijuí: Unijui, 2013.

PIMENTA, S. G. Pesquisa-ação crítico-colaborativa: construindo seu significado a partir de experiências com a formação docente. Educação e Pesquisa, v. 31, p. 521-539, 2005.

SCHON, D. A. Os professores e sua formação. Lisboa: Dom Quixote, 1992.

SOUZA, R. C. R. Novos paradigmas na educação. Mimeo: Rio de Janeiro, 2005.

TARDIF, M. Saberes docentes e formação profissional. Petrópolis, RJ: Vozes, 2008.

TARDIF, M.; LESSARD, C. O trabalho docente: elementos para uma teoria da docência como profissão de interações humanas. 7. ed. Rio de Janeiro: Vozes, 2012.

TRIVIÑOS, A. N. S. Introdução a pesquisa em ciências sociais: a pesquisa qualitativa em educação. Atlas: São Paulo, 1987.

Recebido em: 23 jun. 2019.

Aceito em: 17 ago. 2020. 